This item was submitted to Loughborough's Research Repository by the author.

Items in Figshare are protected by copyright, with all rights reserved, unless otherwise indicated.

Mutual adjustment processes in international teams: lessons for the study of expatriation

PLEASE CITE THE PUBLISHED VERSION

PUBLISHER

(C) M.E. Sharpe

LICENCE

CC BY-NC-ND 4.0

REPOSITORY RECORD

Zimmermann, Angelika, and Paul Sparrow. 2019. "Mutual Adjustment Processes in International Teams: Lessons for the Study of Expatriation”. figshare. https://hdl.handle.net/2134/3098. 
This item was submitted to Loughborough's Institutional Repository by the author and is made available under the following Creative Commons Licence conditions.

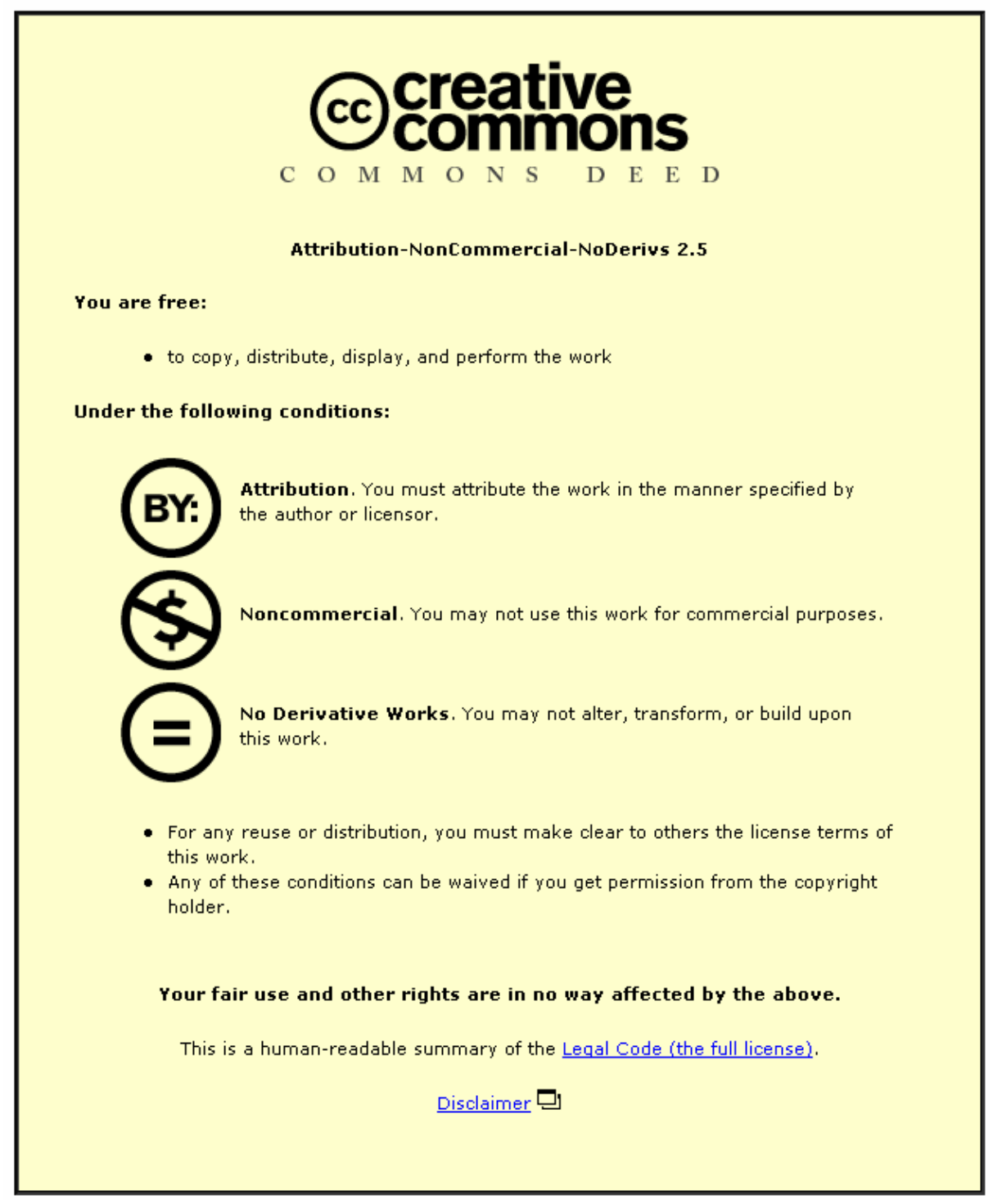

For the full text of this licence, please go to: http://creativecommons.org/licenses/by-nc-nd/2.5/ 


\title{
MUTUAL ADJUSTMENT PROCESSES IN INTERNATIONAL TEAMS: LESSONS FOR THE STUDY OF EXPATRIATION
}

\section{Paper submitted to International Studies in Management and Organisation}

\author{
Dr. Angelika Zimmermann \\ Lecturer in International Business and Strategy \\ Business School, Loughborough University \\ Leicestershire LE11 3TU \\ United Kingdom \\ E-Mail: a.zimmermann@lboro.ac.uk \\ Tel.: +44 (0)1509228848 \\ and \\ Paul Sparrow \\ Manchester Business School, \\ Booth Street West, Manchester, M15 6PB, \\ United Kingdom \\ Tel: 00441612756564 \\ E-Mail: paul.sparrow@mbs.ac.uk \\ Fax: +44 (0)161 2756598
}




\section{ABSTRACT}

Researchers have commonly regarded expatriate adjustment as a unidirectional process of one individual adjusting to a foreign environment. In contrast, we argue that it may be necessary to conceptualise the expatriate's adjustment to social interactions as part of a process of mutual adjustment within an international team. Research on expatriate adjustment can be informed by our study of mutual adjustment in international teams. Eleven teams of four combinations of nationalities - German-English, German-Indian, German-Japanese, and German-Austrian - were examined in two German companies, in a one-year longitudinal study. In-depth interviews and team observations were conducted with 116 participants. From the findings, a model was developed that captures the mechanisms of mutual adjustment at the level of cognitive processes, attitudes, and behaviours of team members. The study also explains how these internal adjustment components are influenced by a number of external context factors. These factors are seen to create a power relationship between the members of the different nationalities in the team. This has a major influence on the direction of adjustment. The findings are discussed with regard to their implications for models of adjustment and forms of capital accrued by global leaders.

\section{INTRODUCTION}

An important focus of expatriation research has been the question of expatriate adjustment. Alternatively referred to as acculturation, adjustment effectiveness, success or satisfaction, it has been viewed as the most important dependent variable related to effectiveness and has driven most theoretical work in the field (Thomas, 1998). However, research has so far been limited to studying adjustment as a unidirectional process of an individual expatriate adjusting to a foreign environment. In contrast, we argue that to achieve a better understanding of the expatriate adjustment process it is necessary to breaden the scope of study and regard expatriates as part of the international teams they work in. The expatriates' adjustment will depend not only on themselves, but also on the adjustment efforts of other international team members. Adjustment can then be understood as a process of mutual interactions rather than a mono-directional process.

This process of mutual adjustment has not been the focus of expatriate adjustment research so far. Surprisingly, mutual adjustment has (to our knowledge) not been investigated in research 
on international teams, either. A number of performance-relevant team processes have however been described which are tied to mutual adjustment processes and therefore suggest that mutual adjustment may play an important part in international team functioning. Such processes include creating a shared understanding (Adler, 1997, p. 142-143; Earley \& Gibson, 2002, p.45), building a 'hybrid culture' (Earley \& Mosakowski, 2000), and the 'integration of differences' (Maznevski, 1994, p.537; Zeutschel, 2002, p.467).

To shed more light on the processes of mutual adjustment relevant for expatriates, we conducted an in-depth, longitudinal study of eleven bi-national teams, including four nationalities. Two broad research questions guided the study:

1. What international differences in work practices and interaction styles do team members perceive to cause difficulties and require adjustment?

2. How is mutual adjustment seen to take place?

To frame these mutual adjustment processes, we drew on previous definitions of sojourner adjustment and on concepts of adjustment 'modes'. We will now explain these concepts, and will develop our argument for the relevance of mutual adjustment processes in the study of expatriatiation in more depth.

\section{THEORY}

Researchers on expatriate adjustment have commonly regarded adjustment as a process of an individual achieving a fit and reduced conflict between his/her own inclinations and the (conflicting) demands of a foreign environment with regard to work, social interactions, and the non-work environment (Berry et al., 1987; Black, Mendenhall, \& Oddou, 1991; Nicholson, 1984). The expatriate's adjustment to social interactions has been modelled as a unidirectional process of one individual adjusting to a foreign environment. Acculturation and expatriate adjustment researchers usually consider a general definition of adjustment, based on person-environment fit models, in which adjustment is commonly understood as the behavioural and internal (e.g., attitudinal, emotional) changes occurring in the individual in a direction of increased 'fit' and reduced conflict between the environmental demands and the individual's behavioural and attitudinal inclinations. Adjustment in turn can be broken down 
into three facets: 'psychological adjustment' (changes of psychological and emotional states characterised by feelings of well-being and satisfaction); 'interaction adjustment' (the individual's behavioural and attitudinal changes with regard to intercultural interactions characterised by the ability to 'fit in' and 'negotiate interactive aspects of the new culture); and 'work adjustment' (changes in reaction to the new job). All three dimensions of adjustment are triggered when incongruence (or conflict) occurs between the individual and environment, i.e. the general environment, social interactions, or the new work. This discrepancy presents an obstacle that has to be removed for the individual to maintain mental well-being and to function normally.

Given progressive globalisation of human resource management (HRM), however, we argue that rather than examining how an individual achieves a fit with a passive environment, we should take into account how other people in the environment - host country nationals and international team members - have an active involvement with the expatriate and influence the adjustment process. There is increasing support for this view in the literature, though as yet scant empirical evidence. Reviewing work on expatriate adjustment, Mendenhall, Kühlman, Stahl and Osland (2002, p.169) noted that “... most empirical research in the field examines the expatriation process from a one-sided perspective, focusing solely on accounts of expatriate managers. Few empirical studies have included the host country perspective". They argued that we need more cross-border research regarding what occurs when two diverse groups begin interacting with one another. This is an example of what Sackmann and Phillips (2004) call the intercultural interaction perspective (the other two research perspectives are labelled cross national comparisons and multiple cultures). They believe that the intercultural interaction perspective “... has demonstrated the importance of contextual analysis and process orientation in cultural research... [and] the resulting thick descriptions reveal insights about the emergence and negotiation of culture and shed light on issues of intercultural communication in the workplace" (p.375). We need to see studies conducted in more realistic multi-cultural contexts and focus investigation on the dimensions that emerge within groups that helps to characterise how they deal with a particular context. Sackmann and Philips (2004) argue that to understand such coping we must understand the skills that are needed to work, navigate and manage in cross-cultural contexts and that enable us to maintain multiple and partial identities. 
Sparrow (2006) has noted that a further modification is therefore important in developing the intercultural interaction research perspective. This is the need to understand mutual adjustment processes (multiple mutualities between team members of several different nationalities). This shift to study of mutual adjustment is important for a number of reasons:

1. On their assignment expatriates increasingly have to cooperate with host country nationals, and therefore frequently have to rely on their assistance (Zimmermann, Sparrow, \& Holman, 2003). Moreover, expatriates often have to work as part of an international team both within the subsidiary, and across different countries.

2. As seen in the new international employee categorisations, not all employees on foreign assignment today can be considered as traditional expatriates. Briscoe and Schuler $(2004$, p. 223) note that: “... the tradition of referring to all international employees as expatriates - or even international assignees - falls short of the need for international HR practitioners to understand the options available...and fit them to evolving international business strategies". In terms of global workforce planning we often now prefer to talk about international employees (IEs) rather then the more traditional idea of expatriates and categorisation of international assignee, parent country national, host country national or third country national. International employees include international commuters, employees on long-term business trips, assignees on short term or intermediate term foreign postings, permanent transferees or permanent cadre, international transferees (moving from one subsidiary to another), immigrants, returnees, contract expatriates, or virtual international employees in crossborder project teams. This study focuses on the latter category of international employee.

3. Erez and Gati (2004) note that cultural commonality - shared meaning systems - can be formed at a number of levels: individual (self representation), group, organizational, national and global. People develop multiple identities - part of which might be driven by a sense of belonging to a (universalistic) global culture part of which is driven by local (tribalistic) identities based on socialisation processes: "... the ability to simultaneously maintain these two types of identity depends on the similarity between the global and local culture... exposure to the global work environment shapes a global identity. A fit between the global and local identity enables effective adaptation to both environments" (Erez and Gati, 2004, p. 593). 
International teams represent the most attractive unit of analysis to evidence (or not) these accelerated processes of cultural bridging.

4. As observed by Sackmann and Phillips (2004, p.377), though "[the intercultural interaction perspective] still maintains that national culture is fundamental to interaction and the basis from which non-national cultural groupings emerge, its hitherto bicultural focus could be extended to multicultural interactions".

The focus of our study is then on mutual adjustment within international teams. This both reflects an examination of more contemporary forms of international employee, and informs the traditional expatriation literature. Our study was based on the assumption that differences exist between team members in international teams that may cause difficulties in the collaboration. In such circumstances mutual adjustment will be required in order for the team to function well. An expatriate's adjustment therefore should not be examined in isolation, but should be understood as a dynamic, complex series of mutual interactions. Adapting the person-environment model noted above, mutual adjustment is therefore defined as the process by which members of different nationalities achieve a fit and reduced conflict between each other, with regard to their differences in work practices and interaction styles.

To gain a better understanding of mutual adjustment in international teams, we return to the early acculturation literature and distinguish between different adjustment 'modes' drawing upon contingency theories of acculturation and expatriate work adjustment. Four Modes of acculturation were classically defined by Berry et al. (1987), constructed from a combination of two dimensions: the degree to which individuals maintain their own culture and identity during acculturation (value of own identity); and the degree of actual contact and resultant participation with the other culture (value of relationship). When both value of relationship and own identity are high then integration results. High relationship value but low identity value results in assimilation. High identity value but low relationship value results in separation, and low relationship value and low identity value results in marginalisation.

Modes of (expatriate) work adjustment have been described by Black et al. (1991) and Nicholson (1984) again from the perspective of two contingencies: the degree to which individuals change or maintain their own attitudes and behaviours; and the degree to which individuals change the work environment. High change in own behaviours and high change in the work environment leads to patterns of exploration, becoming absorption if the work 
environment is not changed. Low change in own behaviours results in determination when the work environment is changed or replication when it is not.

By drawing on these conceptualisations, it is possible to define modes of adjustment that apply to international teams. We can assume that the importance of relationships is given the relationships in the team are mandated by the structure and charter. Therefore modes of adjustment have to be constrained to either integration or assimilation. We then take the construct of own behaviour change and explore this in a mutual context to differentiate whether integration or assimilation will result. Our model is again based on the combination of two dimensions: the degree to which members of one nationality in the team change their own attitudes and behaviours in order to achieve a fit with the other nationality; and the degree to which attitudes and behaviours are changed on the side of another nationality in the team. Given the case of a bi-national team, it is then possible to distinguish four modes of adjustment (see Figure 1).

Figure 1 about here

We name the modes on the basis of Berry et al.'s (1987) terminology. The mode where changes occur mainly on one own's side is called 'Own assimilation'. The mode where changes occur mainly on the other nationality's side is termed 'Other party assimilation'. These equivalent terms are chosen to capture the bi-directional aspect of adjustment. 'Integration', in turn, is the mode whereby both sides change their attitudes and behaviours, whilst 'Separation' is the mode designating that changes take place on neither side. In the same vein, it is possible to describe the adjustment modes in terms of the 'direction' of adjustment, which is the extent to which each side changes attitudes and behaviours in comparison to the changes on the other side. These definitions were taken as a basis for this study.

\section{METHODOLOGY}

\section{Research strategy}

The aim of this study was to examine the role of mutual adjustment in international teams through use of case studies. Case studies are not a research method as such, but a research 
strategy (Hartley, 2004). They consist of detailed investigations, often with data collected over a period of time, of a particular phenomenon in its context. A case study may be one or more organizations, or groups and individuals operating within an organization and may focus on a number of levels of analysis, ranging from public policy events through to individual psychology. The aim here was to understand how behaviour or processes - in this case mutual adjustment processes within international teams - were influenced by and influenced this context. Access was therefore needed to a number of different teams inside these case study organizations. Moreover, the case studies needed to represent a set of identifiable and important contexts.

- A social constructivist approach (Gergen, 1985) was taken, which assumes that people construct their individual reality as well as a shared reality through their social interactions. The research focus was directed towards individuals' experiences rather than towards objective 'facts'. This allowed us to develop theory in an inductive manner, necessary given the lack of empirical research on international teams.

The social constructivist perspective led to the choice of qualitative methods for this study. These methods impose the least structure on the participants and are therefore open to themes that are not anticipated by the researcher, but are part of the participants' subjective realities.

\section{Sample}

If we are to move beyond our currently limited views of expatriate adjustment, then we need more research that employs longitudinal designs and that includes the host country perspective on the determinants, processes and outcomes of adjustment (Mendenhall et al, 2002). This study incorporates these two requirements. In-depth interviews and team observations were conducted with 116 participants over a one-year period. The participants were selected using theoretical sampling (Glaser \& Strauss, 1967). Choice of participants was guided first by the initial research aims as well as the possibilities of access. Individual teams and participants were added to the research to scrutinise emerging themes and new theoretical claims. 11 bi-national teams were studied in two German companies, a bank and an electronics company. The teams consisted of four different combinations of nationalities. At the bank, two German-English teams took part (responsible respectively for international business management and for implementing IT systems). In the electronics company, five 
German-Indian, two German-Japanese, and two German-Austrian teams were examined (teams were tasked with developing software functions for electronic control units to be used in car engines). Data were collected in an exploratory stage and then in two planned stages over the year. The design served to detect whether the participants had changed their views over time and whether the status and nature of their mutual adjustments had changed. As some teams had a previous history and adjustment could be influenced by organizational socialization processes, the study included not only real-time adjustment, but also retrospective reports on changes that had occurred before the first stage of data collection. Qualitative interviewing served as the main method of data collection. Interviews were increasingly structured over the year following the emergence of the main themes. Questions remained open-ended up to the end of the study.

Naturalistic observations were also conducted in management and team meetings, international workshops, meetings with the end customer, and informal discussions amongst team members and managers. This served to provide further background information on the work and collaboration issues involved, and managerial strategies. Documents, such as meeting minutes, presentations on managerial strategies, and summaries of collaboration difficulties were compared to the interview findings.

\section{Data analysis}

Data analysis followed the principles of grounded theory, beginning with 'open coding' (Strauss \& Corbin, 1990) at the exploratory stage (it was possible immediately to discern themes that were important in the eyes of the participants) but at the same time a number of theoretical concepts and the distinction between differences in terms of work practices and interaction styles, interaction processes and factors of adjustment, and the concept of adjustment 'modes' were used as more general templates for analysis in addition to the open coding procedure. Themes and corresponding codes were refined in an iterative process of data collection and analysis after each interview and each day of interviewing. In the time between the data collection at the different sites, interview transcripts were coded according to the scheme that had emerged during the interviewing phase. In a procedure of axial coding (Strauss \& Corbin, 1990), categories were further clustered and divided into hierarchies of subcategories, and the most apparent causal relationships were noted. This analysis led to an overall summary of perceived national differences, as well as components and factors of 
adjustment at each site. These summaries were used as a basis for feedback reports to the participants, which were used to provide some participant validation. A final analysis was conducted after all data were collected. 100 interviews - those of the participants who had taken part in both stages of data collection - were imported and coded in the qualitative data analysis package NVivo (Version 12; 2000). All interviews were re-coded using the final categorisation scheme.

The next step was to develop a model of mutual adjustment across the participating sites using a comparative analysis on three dimensions: different sites; different participant groups within a site (in particular members of different nationalities); and more or less successful teams. This analysis served to determine causal relationships between factors, processes, and outcomes of adjustment. A negative case analysis was executed when certain participants or teams had given contradictory answers regarding any of the themes, searching for intervening factors which would explain these differences. In this manner, a model of mutual adjustment across the participating sites was developed. The model was saturated when the analysis led to no further modifications.

\section{RESULTS}

At each of the four participating sites, differences in work practices and interaction styles were seen to impede work and interactions of the international teams, making it necessary for team members to adjust to each other. An overview of the differences and the modes by which adjustment occurred is given in Table 1.

- Insert Table 1 about here -

\section{Adjusting to differences in work practices}

The study allowed for comparison of both work practices and interaction styles as initiators of adjustment needs. Differences between the core German nationals and four other nationalities could be examined. In relation to the first adjustment need - work practices - different factors dominated adjustment needs in each national pairing. In the German-English teams, a major difference was seen in German colleagues spending more time on planning and problem analysis, for example when developing IT systems and business plans. This style achieved 
more sustainable results, but did not allow for quick responses to the investment market and business opportunities had thereby been lost. Over the course of data collection, Germans adjusted through the mode Own assimilation, starting to improvise more and avoid unnecessary problem analyses. At the German-Indian site, a significant difference in working practices reported was Indian colleagues having more difficulty completing software coding in an independent manner and anticipating possible difficulties. This was attributed to their lack of know-how regarding the system and the car engine. Problems of product quality, such as software bugs, resulted. Indian colleagues adjusted by mode Other party assimilation increasingly learning to work more independently, and they gained more know-how. The German-Japanese teams struggled with their different approach to dealing with the Japanese customer. Japanese colleagues hardly ever refused customer requests, to the extent that the product had to be changed shortly before the delivery deadline and financial losses were made. Adjustment here occurred through Integration. German colleagues increasingly let the Japanese side conduct the negotiations with the customer, whilst Japanese colleagues started to negotiate customer requests to a larger extent. Finally, in the German-Austrian teams, adjustment was necessary regarding a different focus on global and local software solutions. Austrian colleagues did not always use the products available in the software platform, developing their own solutions in order to respond to pressures from the local customer. Separate software branches had to be mainained in Austria, which required extra capacities and costs. Adjustment was possible through Integration. German colleagues increasingly took into account the local customer needs when developing platform products. The Austrians, in turn, started to ask for platform solutions more often before developing their own software branch. Conflicts about this issue decreased.

\section{Adjusting to differences in interaction styles}

The second area of difference was in terms of interaction styles. These showed great similarities across the sites. Differences with regard to implicit and explicit expression were the main trigger of interaction adjustment in the German-English, -Indian and -Japanese teams. German colleagues were seen to be more explicit in their statements and less sensitive towards implicit messages, leading to misunderstandings (for example when Germans did not understand that the other side had implicitly stated their difficulties). Integration was the principal mode of adjustment. Germans learned to read between the lines, whilst the other side learned to be more explicit. In the German-Austrian teams, the style of criticising was 
the main issue for adjustment. Austrians were seen to criticise more frequently and in an exaggerated manner. This could lead to offence and conflicts. Adjustment occurred by the mode Own assimilation, as the German side increasingly understood that Austrian criticisms were meant to stimulate a discussion rather than arguments. Germans therefore felt less offended, and the conflicts decreased.

\section{Internal adjustment components}

From the results across the four sites a model was developed to explain how the process of mutual adjustment occurred (see Figure 2). The model describes the adjustment process at two levels: internal adjustment components (i.e. cognitive processes, attitudes, and behaviours of team members); and contingent external context factors. Five internal adjustment components were identified: communication; change of views; evaluation of differences; negotiation; and teaching-control. Where necessary, each of these components was further sub-divided into different actions. These internal adjustment components highlight the cognitive, affective and behavioural skills that become important for expatriates when working through international team structures.

Figure 2 about here 
Communication. Three different kinds of communication played a role in the adjustment process: solution-seeking, rule signalling and relationship-building. Solution-seeking involved the exchange of knowledge and information about work problems in order to come to work solutions, leading directly to behaviour changes on two sites with regard to work practices. Rule-signalling represented a meta-communication about rules and norms that helped avoid misunderstandings concerning differences in work practices as well as interaction styles. It occurred mainly in cases where critical problems occurred, and during socialising, rather than in everyday work interactions. Relationship-building helped create trust as a foundation for solution-seeking and rule-signalling behaviour. It was also important for gaining mutual understanding and increasing the willingness to adjust. Communication of all kinds was necessary for achieving a new level of understanding (for example. a change of views) of the differences between the nationalities.

Change of views. The views of several participants about differences in work practices and communication styles (and associated difficulties) changed over time. Both before and within the period of data collection, participants developed a greater awareness and understanding of the others' approach. This lead to new evaluations of the others' approach and formed part of the adjustment process to both work and interactions. For interaction adjustment it was a crucial precondition for directly modifying one's own style of communicating and for avoiding misunderstandings and offence. Changing views were triggered primarily by creation of different information sources deriving from four processes. Individual experience and socialisation by the ingroup (i.e., by members of one's own nationality) were the primary sources on all sites. Given a certain amount of trust, views were also developed through socialisation by the outgroup (i.e., members of the other nationality). Some views were also taught officially, through socialisation by the organisation, for example on intercultural workshops. Such changes of view affected team members' evaluations of the differences as well as their attitudes on who should be responsible for adjustment.

Evaluation of differences: adjustment attitudes. Participants on the two sides of each team made different judgements about their own and the other nationality's particular work practices and interaction styles. They either favoured their own, the other or both approaches. These evaluations changed both before and within the period of data collection. Evaluations corresponded mostly to an attitude about which side should change their behaviour in order to achieve a fit between the two sides. These attitudes in turn were associated with the actual 
distribution of changes between the two sides - i.e., the adjustment mode. For example, in the German-English teams, both sides learned to appreciate the advantages of choosing either a more planned or a more spontaneous approach, depending on the nature of the task. Germans changed their practices when they could not convince their English bosses, resulting in an adjustment mode 'Own assimilation'.

Negotiation. Different views concerning the approach to be taken sometimes had to be negotiated between the nationalities in a team, directly related to the modes of work adjustment. When one side demanded changes, this could lead to changes on the other side, if the other side was either convinced, conceded, or agreed on the change. Such negotiations were particularly relevant to work adjustment where differences could be related to work outcomes.

Teaching and control. To achieve the changes that had been negotiated, it was sometimes necessary to take actions of teaching and control. English bosses tended to teach business practices to German colleagues and sometimes set tight deadlines in order to initiate control, which supported the adjustment mode 'Own assimilation'. Similarly Germans had to teach Japanese colleagues about platform requirements and profit-oriented negotiation procedures, whilst Japanese team members gave assistance with implicit Japanese customer demands. In the German-Austrian teams, Germans were the ones to teach Austrian colleagues on platform solutions, whilst Austrians had to explain the local needs to German team members. In both cases, this facilitated the adjustment mode 'Integration'.

\section{External context factors}

In addition to identifying the internal adjustments (and requisite skills) a number of factors beyond the sphere of influence of the international teams also had a major influence on the way in which individuals changed their behaviours and attitudes in order to adjust to differences. The external context factors were interrelated and either combined or competed with each other in their influence on the adjustment modes. Four factors dominated: nationality of headquarters; nationality of leadership; external customers; and globalisationlocalisation strategies.

Nationality of headquarters. The nationality of headquarter impacted the way team members changed both work practices and communication styles. Three elements were important here: 
organisational culture and regulations guided work practices across the countries; globally standardised practices and structures were designed at headquarters, to co-ordinate activities across nations; and headquarter membership allowed for greater access to information. Due to the influence of these headquarter features, the German nationality of headquarters increased German members' power to demand and achieve changes of the other nationalities' work practices and communication styles towards the German approach. It allowed Germans greater access to background information and know-how, which justified them in demanding and teaching more "know-how". Nationality of headquarters influenced the adjustment components and the adjustment modes. With regard to previous power definitions, the nationality of headquarters provided two different sources of power: 'bureaucratic' power legitimised requests for the other side to adhere to rules (Weber, 1947); 'network centrality' where headquarter members were interconnected with a greater number of departments and subsidiaries of the company and therefore had a more central role within global workflows (Tichy \& Fombrum, 1979). This reinforced their power to demand subsidiary members to maintain the global standards.

Nationality of leadership. The nationality of leadership was another factor that influenced the shape of the internal components, and the direction of work and interaction adjustment. Members of one nationality in each team were the formal leader. They therefore had more position power from which to demand changes and control the work practices of either side, which would influence the direction of adjustment. This leadership power can be categorised as 'formal power' in the sense of Pfeffer (1992), and as the 'hierarchical authority' described by Astley \& Sachdeva (1984).

The external customer. The demands of the external customer was another factor impinging upon the differences in work practices and the components and direction of work and interaction adjustment. In each team, one nationality generally worked more closely with the customer than the other did. This side of the team therefore felt the external pressure by the customer far more than the other side. This could strengthen their tendency to demand changes of work practices and communication styles from the other side in order to fulfil customer requirements. They were also the ones who had to teach the other side about customer requirements. In this manner, the external customer factor supported a direction of adjustment towards the side which held the customer interface. The power which was based on the customer interface can be explained in terms of the concept 'resource control' (e.g., 
Astley \& Sachdeva, 1984). In this sense, the external customer is a critical resource for the company, because it heavily influences the company's success. The resource was controlled by the side of the team who held the customer interface and thereby gained the power to demand the other side to fulfil customer requirements.

Management strategies of globalisation and localisation. The managerial globalisation and localisation strategies set the ground for the degree of influence that the nationality of headquarters, the nationality of leadership, and the external customer had on the direction of adjustment. Globalisation strategies consisted of establishing globally standardised practices and structures, and promoting the interests of the company as a whole at the subsidiary. Localisation strategies included delegating responsibilities - such as leadership responsibility, the customer interface, and product development - to the subsidiary. The managerial strategies of globalisation and localisation were therefore critically important in the distribution of power to determine work practices between headquarters and subsidiaries.

The above external context factors had their most striking effect on the adjustment modes through the power balance that they created between the nationalities. This power relationship was a result of the specific constellation of the external context factors on each site. Thus, the power balance firstly depended on which nationality shared the nationality of headquarters, which side held the leadership power, and which one was responsible for the customer interface. The power distribution was also affected by the degree to which product development (such as financial responsibilities, the software development, and the necessary know-how) was localised - i.e., located at the subsidiary - or globalised and located at headquarters. The management strategies of localisation and globalisation, in turn, laid the ground for this distribution of leadership, customer interface, and product development between the countries. The specific constellation of these factors led either to a power struggle or to a clear power balance between the two nationalities. This power balance, in turn, determined the direction of adjustment either towards both sides, leading to a mode 'Integration', or towards one side more than the other, which resulted in the mode 'Own assimilation' and 'Other party assimilation'. The power balance between the nationalities had its effect mainly through its impact on the internal adjustment components 'negotiation' and 'teaching and control' and on team members' actual changes of attitudes and behaviours. More specifically, the power distribution determined whether negotiations and teaching/control between the nationalities were mutual or unidirectional. 


\section{DISCUSSION}

We discuss the findings from a theoretical perspective by reference to recent work on: expatriate adjustment models (Mendenhall et al, 2002), and different forms of capital necessary for global leadership (Harvey and Novicevic, 2004).

Expatriate adjustment models can be classified as being driven by assumptions about learning, stress-coping, developmental and personality (Mendenhall et al, 2002). Learning models assume that since expatriate adjustment has to do with learning new skills and techniques of adaptation, the impact of the 'other' culture can be seen as a change in behavioural reinforcement contingencies. The major task facing expatriates is to adjust their social skills such that they can learn the salient characteristics of the new environment in terms of new roles, rules and norms of social interaction. Cross-cultural training was designed on the principle that the rules and values of a new culture had to be learned (and a repertoire of cognitive and behavioural schema and responses developed) before adjustment could take place (Black, Mendenhall and Oddou, 1991). Stress-coping models are based on the assumption that feelings of anxiety, confusion and disruption associated with culture shock are akin to individual stress reactions under conditions of uncertainty, information overload and loss of control. The adjustment reaction is characterised by a variety of symptoms of psychological distress associated with any critical life event. Stress management (coping strategies), rather than stress avoidance, is necessary in order for expatriates to engage in necessary behaviours (Aycan, 1997).

Developmental models tend to highlight phases of adjustment (for example contact, disintegration, reintegration, autonomy and independence) that reflect progressive stages of cultural awareness (Adler, 1983). Individuals undertake adaptive activities only when environmental challenges threaten their internal equilibrium. Processes of periodic (rather than linear) disintegration, regrouping/ regeneration then higher maturation (progressive intercultural sensitivity often also associated with global leadership competence) are an inevitable consequence of exposure to other cultures. In a rare qualitative study of returned expatriate stories, Osland (1995) adapted the metaphor of heroic adventures to note the importance of personal transformations that accompany adjustment processes. Finally, personality-based models argues that such development can in part be predicted by a set of generalisable 
attitudes and traits, such as adaptation, cross-cultural and partnership skills (Kealey, 1996) or personality variables that are associated with model cross-cultural collaborators. The importance of these pre-requisites depends on the nature of the position and task variables, organisation characteristics and host country. Empirical support is however still weak, and again there may be contradictions between what is required for interaction adjustment and work adjustment. Moreover, as Stahl (1998) found in his study of German expatriates assigned to work in Japan and the US, each country may present different problems and conflicts to the expatriates, each requiring different personality-related coping strategies.

Our study supports the initial claim that mutual adjustment is fundamental for international team success. Mutual adjustment was in the participating teams necessary for overcoming the difficulties associated with certain differences regarding work practices as well as communication styles. Mutual adjustment was therefore responsible for achieving better relational and work outcomes. For expatriation research, this suggests that a greater focus should be placed on the mutual adjustment within the international team the expatriate works in. Our study also highlighted the special importance of the interaction processes that were identified as the 'internal adjustment components', namely, certain types of communication, a change of views through different information sources, evaluations of differences, adjustment attitudes, and teaching and control. Many of these components correspond to the suggestions made by expatriation researchers regarding personal competencies (inherent in the personality models noted above) that facilitate expatriate adjustment. In particular, communication and negotiation skills, a willingness to change one's views concerning differences, and the ability to change one's own behaviours are all part of 'intercultural competence', which has been studied frequently (e.g., Gertsen, 1990). This competence includes several competencies such as 'cultural flexibility' (Torbiorn, 1982), referring to one's 'willlingness to modify own behaviours and attitudes', and the proclivity to judge others according to stereotype.

Expatriation research has placed a great emphasis on cultural differences and culture distance as a factor of intercultural adjustment (Aycan, 1997; Berry, 1997). Some of the differences between team members in this study with regard to work practices and interaction styles can be seen as cultural differences. However, cultural differences did not always seem to be the most important differences causing difficulties. Even with regard to the culture combinations with the highest culture distance, Germany-India and Germany-Japan, the differences in work practices were attributed to a large extent to other than cultural reasons. In the Indian-German 
teams, the main trigger for work adjustment was the difference regarding an independent working styles. The Indians' less independent way of working may be attributed to their culture's tradition of more authoritative and less self-determinaned decision making, which corresponds to a higher score on the cultural dimension 'power distance (Hofstede, 1980). However, the less independent working style was attributed primarily to a lack of know-how on the Indian side, which could be tackled with increasing localisation strategies. The influence of know-how was therefore seen to be more important than cultural differences. In the German-Japanese teams, the difference of dealing with the customer was partly explained by the Japanese tradition of the 'keiretsu' system. However, the differences in the approach of dealing with the customer were also explained by the influence of the external context factors, i.e., the nationality of headquarters (requiring standardised procedures), and the location of the customer interface in Japan.

These observations imply that expatriation research has to be careful not to limit itself to examining adjustment to cultural differences when examining work adjustment. Other differences, which are more dependent on the external context factors, may be more critical to adjustment and to the expatriate's success on the assignment. This accords with a learning theory perspective. This study sheds some light on the content of this learning. The behavioural and cognitive schemata necessary for international managers to be effective and to understand their new roles, rules and norms of social interaction have to incorporate a more sophisticated understanding of the host country environment. Rather than somewhat simplified principles about the rules and values of a new national culture having to be learned, learning has to be developed around insights into the nature and mechanisms of national business systems (Whitley, 1999). This implies knowledge about institutions and social systems (as evidenced for example by the need to understand how the customer interface operates in the Japanese keiretsu system).

However, our study also brings home the point that the success of adjustment is not determined by the team members' skills, attitudes, behaviours alone. Harvey and Novicevic (2004, p. 1173) note that global leaders “... have to possess a complex amalgamation of technical, functional, cultural, social and political competencies to navigate successfully the intricacies of changing cross-border responsibilities". They distinguish between social capital (which leads to trust) and political capital (which leads to legitimacy), human capital (which leads to competencies) and cultural capital (which leads to social inclusion and 
acceptance). Whilst the internal adjustment factors had much to do with human capital and social capital, the external context factors had much to do with the building political capital. Accordingly, we found that the expatriate's adjustment within a team was not influenced solely by his or her own competencies. Instead, the power balance between expatriates and other team members (such as host country nationals) is likely to have a major influence on the course of adjustment. Depending on the distribution of the nationality of headquarters, leadership, and the customer interface, the expatriate will have more or less power to demand changes from the other side, and to achieve them through teaching and control.

The distribution of responsibilities and power has been examined closely by researchers discussing the advantages of localisation versus centralisation strategies in international firms (Bartlett and Ghoshal, 1989) and in international mergers and acquisitions (Gertsen, Soderberg, \& Torp, 1998; Navahandi \& Malekzadeh, 1998) and within expatriation research, the influence of the power balance has been studied indirectly as part of the expatriate's hierarchical position. A higher hierarchical position is seen to facilitate adjustment, because such a position allows the expatriate to use more 'active' rather than 'passive' coping strategies, for example in changing organisational rules (Mamman, 1996). How can political and social capital be developed effectively and to the benefit of all team members? Our study suggests that determination (changes on the other side) may not always be the most beneficial adjustment mode. Changes of work practices and interaction styles may be necessary on both sides (for example with regard to explicit and implicit communication styles), or even only on the side of the expatriate, for example when local market conditions have to be adjusted to. To facilitate such 'integration' or 'assimilation', greater localisation of power towards the subsidiary may be necessary. A greater share of responsibilities regarding the customer interface, product development and team leadership may then have to be provided to the other team members, such as the host country nationals. In terms of understanding how appropriate political and social; capital is developed with international management teams, expatriate adjustment research could therefore benefit from taking into account this power distribution between expatriates and other team members to examine how they affect the mode of adjustment. Although there is some linkage here to the use of role theory in stress-coping models, the conclusion is that more insight from the traditional literature on power would seem useful in the context now of international teams. 


\section{CONCLUSION}

In this study we have drawn upon constructs from the expatriate adjustment literature as well as work on different forms of capital that global leaders have to marshal in order to interpret our findings. We have been able to examine mutual processes of adjustment over time and identify the main strategies or processes involved. From this, it is clear that a specific set of skills come to the fore in creating successful adjustments. A series of internal adjustment components were seen to be important in building human and cultural capital. Social and political capital are also important however (Harvey and Novicevic, 2004) and this led us into an examination of the role of power within our international management teams. These considerations allow for the conclusion that the processes of mutual adjustment in international teams may be highly relevant to the adjustment and success of expatriates on their assignment. Expatriation success could be understood better if researchers shifted their focus from the expatriate's unidirectional adjustment towards the process of mutual adjustment between expatriates and other members of their international team. The model developed in this study provides a framework for such investigations, by describing several internal components and external context factors that may be crucial for the successful adjustment of expatriates within international teams. 


\section{REFERENCES}

Adler, N.J. 1983. Cross-cultural management research: the ostrich and the trend. Academy of Management Review, 8, 2, Apr.: 226-32.

Adler, N.J. 1997. International Dimensions of Organizational Behavior, $3^{\text {rd }}$ Ed. Cincinnati: South-Western College Publishing.

Astley, W.G., \& Sachdeva, P.S. 1984. Structural sources of intraorganizational power: A theoretical synthesis. Academy of Management Review, 9(1): 104-113.

Aycan, Z. 1997. Expatriate adjustment as a multifaceted phenomenon: Individual and organizational level predictors. The International Journal of Human Resource Management, 8(4): 434-456.

Bartlet, C. \& Goshal, S. 1989. Managing across borders: The transnational solution. Boston: Harvard Business School Press.

Berry, J.W. 1997. Immigration, Acculturation, and Adaptation. Applied Psychology: An International Review, 46(1): 5-68.

Berry, J.W., Kim, U., Minde, T, \& Mok, D. 1987. Comparative studies of acculturative stress. International Migration Review, 21(3): 491-511.

Black, J.S., Mendenhall, M., \& Oddou, G. 1991. Towards a comprehensive model of international adjustment: An integration of multiple theoretical perspectives. Academy of Management Review, 16, 2, Apr.: 291-317.

Briscoe, D. and Schuler, R.S. 2004. International human resource management, $2^{\text {nd }}$ Edition. New York: Routledge.

Erez, M. \& Gati, E. 2004. A dynamic, multi-level model of culture: from the micro level of the individual to the macro level of a global culture. Applied Psychology: An International Review, 53 (4): 583-598.

Earley, C. \& Gibson, C.B. 2002. Multinational Work Teams. A New Perspective. Mahwah, New Jersey: L.Erlbaum.

Earley, P.C. \& Mosakowski, E. 2000. Creating Hybrid Team Cultures: An Empirical Test of Transnational Team Functioning. Academy of Management Journal, 43, 1, $26-49$.

Gergen, K.J. 1985. The social constructionist movement in modern psychology. American Psychologist, 40, 3, March: 266-275.

Gertsen, M.C. 1990. Intercultural competence and expatriates. The International Journal of Human Resource Management, 1, 3, 341-362.

Gertsen, M.C., Soderberg, A.-M., \& Torp J.E. 1998. Different approaches to the understanding of culture in mergers and acquisitions. In M.C. Gertsen, A.-M. Soderberg, and J.E. Torp (Eds.), Cultural dimensions of international mergers and acquisitions, 39-56, Berlin: de Gruyter.

Glaser, R.D., \& Strauss, A.S. 1967. The discovery of grounded theory: Strategies for qualitative research. New York: Aldine.

Hartley, J. 2004. Case Study Research. In C. Cassell and G. Symon (Eds.) An essential guide to qualitative methods in organizational research. London, Sage. Pp. 323-333. 
Harvey, M. \& Novicevic, M.M. 2004. The development of political skill and political capital by global leaders through global assignments. International Journal of Human Resource Management, 15 (7): 1173-1188.

Hofstede, G. 1980. Culture’s Consequences. Beverly Hills, CA: Sage.

Kealey, D.J. 1996. The challenge of international personnel selection. In D. Landis and R.S. Bhagat (eds.) Handbook of intercultural training. 2nd Edition, pp. 80-105. Thousand Oaks: Sage.

Mamman, A. 1996. A diverse employee in a changing workplace. Organization Studies, 17(3): 449-477.

Maznevski, M. 1994. Understanding our differences: Performance in decision-making groups with diverse members. Human Relations, 47, 531-552.

Mendenhall, M.E., Kühlman, T.M., Stahl, G. \& Osland, J.S. 2002. Employee development and expatriate assignents, In M.J. Gannon and K.L. Newman (eds) Handbook of crosscultural management. London: Blackwell, pp. 155-184.

Nahavandi, A. \& Malekzadeh, A.R. 1998. Leadership and culture in transnational strategic alliances. In M.C. Gertsen, A.-M. Soderberg, and J.E. Torp (Eds.), Cultural dimensions of international mergers and acquisitions, 39-56, Berlin: de Gruyter.

Nicholson, N. 1984. A theory of work role transitions. Administrative Science Quarterly, 29: 172-191.

Osland, J. 1995. The adventure of working abroad: hero tales from the global frontier. San Francisco, CA: Jossey-Bass.

Pfeffer, J. 1992. Managing with power. Boston: Harvard Business School Press.

Sackmann, S.A. \& Phillips, M.E. 2004. Contextual influences on culture research: shifting assumptions for new workplace realities. International Journal of Cross Cultural Management, 4 (3): 370-390.

Sparrow, P.R. 2006. International management: key challenges for industrial and organizational psychology, in G.Hodgkinson (ed) International Review of Industrial and Organizational Psychology. Volume 21. London: Wiley.

Stahl, G.K. 1998. Internationaler Einsatz von Fuehrungskraeften. Munich: Oldenbourg.

Strauss, A., \& Corbin, J. 1990. Basics of qualitative research: Grounded theory procedures and techniques. Newbury Park, CA: Sage.

Thomas, D.C. 1998. The expatriate experience: a critical review and synthesis. In J.L. Cheng and R.B. Peterson (eds.) Advances in international comparative management, Vol. 12, pp. 237-73. Greenwich, CT: JAI Press

Tichy, N.M., \& Fombrum, C. 1979. Network analysis in organizational settings. Human Relations, 32(11): 923-965.

Torbiorn, I. 1982. Living Abroad. New York: Wiley.

Weber, M. 1947. The theory of social and economic organization. New York: Oxford University press.

Whitley, R. 1999. Divergent capitalisms: the social structuring and change of business systems. Oxford: Oxford University Press. 
Zeutschel, U. 2002. Plurikulturelle Arbeitsgruppen. In S. Stumpf \& A. Thomas (eds.), Teamarbeit und Teamentwicklung, Göttingen: Hogrefe, p.461-477.

Zimmermann, A., Holman, D., \& Sparrow, P. 2003. Unravelling adjustment mechanisms: Adjustment of German expatriates to intercultural interactions, work, and living conditions in the People's Republic of China. International Journal of Cross-Cultural Management, 3(1): 45-66. 
FIGURE 1

Modes of mutual adjustment in international teams

Change of attitudes and behaviours on the other side
LOW
HIGH

Change of attitudes and behaviours on one side

\begin{tabular}{|c|c|c|} 
& \multicolumn{1}{c|}{ Leparation } & $\begin{array}{c}\text { Other } \\
\text { assimilation }\end{array}$ \\
\cline { 2 - 3 } HIGH & $\begin{array}{c}\text { Own } \\
\text { assimilation }\end{array}$ & Integration \\
\cline { 2 - 3 } & & \\
\hline
\end{tabular}

TABLE 1

Differences in work practices, interaction styles, and modes of work and interaction adjustment at the four sites

\begin{tabular}{|l|l|l|l|l|}
\hline Site & $\begin{array}{l}\text { German- } \\
\text { English }\end{array}$ & German-Indian & $\begin{array}{l}\text { German- } \\
\text { Japanese }\end{array}$ & $\begin{array}{l}\text { German- } \\
\text { Austrian }\end{array}$ \\
\hline $\begin{array}{l}\text { Differences in } \\
\text { work practices }\end{array}$ & $\begin{array}{l}\text { Long-term } \\
\text { planning and } \\
\text { problem analysis }\end{array}$ & $\begin{array}{l}\text { Independent } \\
\text { working and } \\
\text { know-how }\end{array}$ & $\begin{array}{l}\text { Approach to } \\
\text { dealing with the } \\
\text { customer }\end{array}$ & $\begin{array}{l}\text { Focus on local } \\
\text { versus global } \\
\text { solutions }\end{array}$ \\
\hline $\begin{array}{l}\text { Mode of work } \\
\text { adjustment }\end{array}$ & Own assimilation & $\begin{array}{l}\text { Other party } \\
\text { assimilation }\end{array}$ & Integration & Integration \\
\hline $\begin{array}{l}\text { Differences in } \\
\text { interaction } \\
\text { styles }\end{array}$ & $\begin{array}{l}\text { Explicit } \\
\text { expression and } \\
\text { direct criticism }\end{array}$ & $\begin{array}{l}\text { Explicit } \\
\text { expression and } \\
\text { direct criticism }\end{array}$ & $\begin{array}{l}\text { Explicit and } \\
\text { implicit } \\
\text { expression }\end{array}$ & $\begin{array}{l}\text { Style of } \\
\text { criticising }\end{array}$ \\
\hline $\begin{array}{l}\text { Mode of } \\
\text { interaction } \\
\text { adjustment }\end{array}$ & Integration & Integration & Integration & Own assimilation \\
\hline
\end{tabular}


FIGURE 2

Model of Internal Components and External Factors of Adjustment



